\title{
DENTIST-PATIENT COMMUNICATION AS PERCEIVED BY PATIENTS IN RIYADH, SAUDI ARABIA
}

\author{
AZIZAH AL-MOBEERIEK \\ College of Dentistry, King Saud University, Riyadh, Saudi Arabia \\ Department of Maxillofacial Surgery and Diagnostic Sciences
}

\begin{abstract}
Objectives: The aim of this study was to assess patient-dentist communication and to evaluate the factors affecting it among Saudi patients and its effect on satisfaction. Materials and Methods: A self-administered questionnaire was designed for this survey with 5-scale Likert-type statements. Results: Patients' main concern was the courtesy followed by information interaction, moral support, explaining the procedure and understanding of the patient's feelings. These were the factors that contributed positively to good communication and satisfaction. Conclusion: It could be concluded that Saudi dentist possess a satisfactory ability to communicate with their patients.
\end{abstract}

Key words:

Dentist, Patient communication, Saudi Arabia

\section{INTRODUCTION}

Dentist-patient communication is a major factor for both health care providers and administrators. It designates doctor-patient interaction and relationship and includes interpersonal relations, information exchange and treatment decision [1].

In fact, those who interacted with the patients, were perceived significantly more competent than others [2].

Dentist behaviour has been associated with more satisfaction and less anxiety [3,4]. Among patients, dentists' communicativeness and informativeness were rated as being the most important traits $[2,5,6]$. As a matter of fact, ideal dentist was characterized as having five factors including mutual communication and fair support $[2,6,7]$.
A patient-centered model of communication has been recommended. This type of communication involves focusing on the patient's needs, values and wishes. Proper communication has been reported to improve patient trust and satisfaction [8]. Further; it reduces risk for adverse events, increases appropriate prescribing and efficiency of practice $[8,9]$. Other benefits of effective communication include patient compliance and understanding $[8,10]$. Communication strategies and information exchange is affected by both patient and doctors' characteristics. Female doctors tend to be more patient-centered in communication [11]. Patients tend talk more when the physician is a woman [11]. Perceived importance of health information delivery and patients' social economic status and self-confidence are also reported to affect the style and degree of communication [10,12-14].

Received: July 4, 2011. Accepted: August 28, 2011.

Address reprint request to A.F. Al-Mobeeriek, Department of Oral Medicine and Diagnostic Sciences, College of Dentistry, King Saud University, Riyadh, Kingdom of Saudi Arabia (e-mail: azizafm2001@yahoo.com). 
Most of the dental schools do not teach communication. Dentists, thus, graduate without appreciating how well the information is being received, understood, and applied during communication [15].

In general, a clear gap in communication between dentists and patients, leading to frustration on both sides, has been reported [16,17]. It is thus suggested that dentists should be trained to enhance their communicative and informative skills [17].

Dentist-patient communication has not been studied among dental patients in Saudi Arabia. The change in life style, globalization, may affect attitude and awareness of patients, and demands the exploration of such a relation and its subsequent enhancement. The aim of this study was to assess patient-dentist communication and to evaluate the factors affecting it among Saudi patients and its effects on satisfaction.

\section{MATERIAL AND METHODS}

\section{Sample and Survey Instrument}

A sample of Saudi patients of various age groups and educational levels were selected from both public and private dental sectors in Riyadh, Saudi Arabia.

A self-administered questionnaire was designed for this survey with 5-scale Likert-type statements. A pilot study was carried out to test the questionnaire on thirty patients at both public and private clinics, and appropriate modifications were made. The questionnaire was distributed randomly to all patients who were 15 years old or above and attended the clinics during the study period. All participants were interviewed and the study's aim, method and any uncertainties were explained prior to filling up of the questionnaire. All patients participated voluntarily and were assured the data collected would be used only for the specified research purposes. They were asked to fill in a questionnaire asking questions about their dentistpatient relationship and their demographic data.
The questionnaire consisted of three parts; the first part contained patient's demographic data, such as age, sex, and level of education, the type of the last dental treatment received, and the qualifications of the treating dentist. The second part contained information on patient satisfaction about the quality of dental care and communication of the treating dentist. The third part contained details of dentist-patient relationship; the patients were asked to respond to a list of 17 questions on dentist behaviour thought to be associated with positive dentistpatient interaction, in Likert-scale type statements.

\section{Statistical Analysis}

Collected data were analysed using the SPSS pack. Simple descriptive statistics, factor analysis, Anova, T-tests, Friedman Test, Chi-square test and Pearson correlation coefficient were used to determine the relationship between the variables of the two parts of the questionnaire.

\section{RESULTS}

\section{Response rate and socio-demographic data}

The response rate was $74.098 \%$ (452/610). More than half of the respondents received their treatment in the public sector 266 (58.8\%), while $186(42.2 \%)$ were treated in the private clinics. There were 211 (46.7\%) males and $241(53.3 \%)$ females. The age-group 15-20 years constituted $43.8 \%$ of the respondents followed by 21-30 years age group (21.0\%) and the people older than 50 years (4\%). As regards the education, there were 34 (7.5\%) illiterates, 298 (65.9\%) were high school level or below, and $120(26.5 \%)$ had a university degree or higher education. Of the 452 respondents $69.2 \%$ $(\mathrm{n}=313)$ were treated by general practitioners and $30.8 \%$ $(\mathrm{n}=139)$ were treated by specialists.

\section{Communication data}

The response results are summarized in Table 1. Overall, there was a general positive agreement as regards dentists' behavior. More than half of the sample (53.5\%) was 
Table 1. Satisfaction scores among patients

\begin{tabular}{|c|c|c|c|c|c|}
\hline Statement & $\begin{array}{l}\text { Strongly } \\
\text { disagree }\end{array}$ & Disagree & Don't know & Agree & Strongly agree \\
\hline $\begin{array}{l}\text { I am satisfied with the duration of the } \\
\text { appointment** }\end{array}$ & $27(6.0)$ & $97(21.5)$ & $30(6.6)$ & $215(47.6)$ & $83(18.4)$ \\
\hline $\begin{array}{l}\text { I am satisfied with the appointments' } \\
\text { frequency** }\end{array}$ & $28(6.2)$ & $121(26.8)$ & $20(4.4)$ & $185(40.9)$ & $98(21.7)$ \\
\hline $\begin{array}{l}\text { I am satisfied with the quality } \\
\text { of treatment }\end{array}$ & $9(2.0)$ & $18(4.0)$ & $41(9.1)$ & $242(53.5)$ & $142(31.4)$ \\
\hline $\begin{array}{l}\text { I am satisfied with the disinfection } \\
\text { and sterilization*** }\end{array}$ & $7(1.5)$ & $29(6.4)$ & $36(8.0)$ & $167(36.9)$ & $213(47.1)$ \\
\hline $\begin{array}{l}\text { I am satisfied with the explanation } \\
\text { given by the dentist }\end{array}$ & $7(1.5)$ & $39(8.6)$ & $36(8.0)$ & $201(44.5)$ & $169(37.4)$ \\
\hline $\begin{array}{l}\text { The dentist warned me when he felt } \\
\text { the procedure might hurt }\end{array}$ & $23(5.1)$ & $43(9.5)$ & $33(7.3)$ & $204(45.1)$ & $149(33.0)$ \\
\hline $\begin{array}{l}\text { Criticized my teeth or how I've been } \\
\text { taking care of them* }\end{array}$ & $31(6.9)$ & $106(23.5)$ & 84 (18.6) & $153(33.8)$ & $78(17.3)$ \\
\hline $\begin{array}{l}\text { Showed that he took seriously what } \\
\text { I had to say** }\end{array}$ & $13(2.9)$ & $46(10.2)$ & $64(14.2)$ & $165(36.5)$ & $164(36.3)$ \\
\hline $\begin{array}{l}\text { Made sure that I was numb before } \\
\text { working on me }\end{array}$ & $10(2.2)$ & $20(4.4)$ & $33(7.3)$ & $169(37.4)$ & $220(48.7)$ \\
\hline $\begin{array}{l}\text { Showed that he knew what I was } \\
\text { feeling }\end{array}$ & $9(2.0)$ & $39(8.6)$ & $81(17.9)$ & $207(45.8)$ & $116(25.7)$ \\
\hline $\begin{array}{l}\text { Encouraged me to ask questions } \\
\text { about my treatment }\end{array}$ & $21(4.6)$ & $62(13.7)$ & $71(15.7)$ & $191(42.3)$ & $107(23.7)$ \\
\hline $\begin{array}{l}\text { Used words that were understandable } \\
\text { in talking about my dental care }\end{array}$ & $6(1.3)$ & $35(7.7)$ & $51(11.3)$ & $214(47.3)$ & $146(32.3)$ \\
\hline $\begin{array}{l}\text { Told me what he was going to do } \\
\text { before starting to work }\end{array}$ & $11(2.4)$ & $31(6.9)$ & $28(6.2)$ & $200(44.2)$ & $182(40.3)$ \\
\hline $\begin{array}{l}\text { Made sure that I do not feel } \\
\text { pain during the procedure }\end{array}$ & $13(2.9)$ & $47(10.4)$ & $64(14.2)$ & $164(36.3)$ & $164(36.3)$ \\
\hline Was patient with me & $5(1.1)$ & $32(7.1)$ & $45(10)$ & $185(40.9)$ & $185(40.9)$ \\
\hline Worked quickly but didn’t rush & $5(1.1)$ & $22(4.9)$ & $54(11.9)$ & $181(40.0)$ & $190(42.0)$ \\
\hline Smiled & $37(8.2)$ & $83(18.4)$ & $44(9.7)$ & $178(39.4)$ & $110(24.3)$ \\
\hline $\begin{array}{l}\text { Let me know that he'd do everything } \\
\text { he could to prevent pain }\end{array}$ & $5(1.1)$ & $31(6.9)$ & $16(3.5)$ & $208(46.0)$ & $192(42.5)$ \\
\hline $\begin{array}{l}\text { Asked me during the procedure if } \\
\text { I were having any pain }\end{array}$ & $11(2.4)$ & $38(8.4)$ & $41(9.1)$ & $172(38.1)$ & $190(42.0)$ \\
\hline $\begin{array}{l}\text { Gave me moral support during the } \\
\text { procedure }\end{array}$ & $18(4.0)$ & $33(7.3)$ & $20(4.4)$ & $227(50.2)$ & $154(34.1)$ \\
\hline
\end{tabular}

$*$ Sig among females $\mathrm{p}=0.000,{ }^{*}$ Sig $\mathrm{p}>0.005,{ }^{* *}$ Sig $>$ high school $\mathrm{p}>0.05$. 
satisfied with the treatment quality and this was significant among younger age group (15-20 years). Around fortyone percent $(40.9 \%)$ were satisfied with the appointment frequency and $47.6 \%$ were satisfied about the duration of the appointment at $\mathrm{p}<0.005$. Around half of the sample $(48.7 \%)$ strongly agreed that their dentist would ensure anesthesia before starting the surgery. Nearly forty-five percent (45.1\%) agreed that their dentist would warn them when the procedure was going to be painful and $44.5 \%$ were satisfied about the procedure explanation. Forty seven percent were satisfied with the disinfection and sterilization and this was significant among individuals with an education above high school at $p>0.05$. One hundred fifty three $(33.8 \%)$ patients indicated that their dentists criticized their oral hygiene and this was significant among females at $p=0.000$. Considering patient's sayings was significant among general practitioners at $p>0.005$.

Correlation matrix showed the appropriateness of the data for factor analysis, few cases showed a correlation above 0.3 which is acceptable level. Kaiser-MeyerOlkin Measure of Sampling Adequacy is 0.818, it is more than 0.6, thus in an acceptable level to perform factor analysis for the presented data. In addition, Bartlett's Test of sphericity was significant (0.0001). Based on the later, four factors were highlighted to be rotated for the final factor analysis with the method of Principal components analysis. The names of the factors were created based on the meaning of the variables included in each factor (Table 2). Using the Rotated Component Matrix and the Extraction Method, rotation method was Varimax with

Table 2. Factor loadings, mean score of questionnaire items

\begin{tabular}{lcc}
\hline \multicolumn{1}{c}{ Items } & Loading & Mean \\
\hline Courtesy & & 4.19 \\
Asked me during the procedure if I were having any pain & 0.745 & 0.732 \\
Was friendly to me & 0.666 \\
Smiled & 0.579 \\
Gave me moral support during the procedure & 0.579 \\
Was patient with me & \\
Understanding & 0.926 \\
Showed that he took seriously what I had to say & 0.923 \\
Showed that he paid attention to what I said & 0.609 \\
Worked quickly but didn't rush & & 3.86 \\
Instructions & 0.710 \\
Made sure I was numb before working on me & 0.696 \\
Asked during the procedure if I were having any discomfort & 0.669 \\
Used words that were understandable in talking about my dental care & 0.582 \\
Showed that he knew what I was feeling & 0.489 \\
Told me what he was going to do before starting to work & \\
Preparation & -0.806 \\
Criticized my teeth or how I've been taking care of them & 0.573 \\
Encouraged me to ask questions about my treatment & 0.504 \\
Warned me when he felt the procedure might hurt & 3.51 \\
\hline
\end{tabular}


Table 3. Types of practice versus dentist communication

\begin{tabular}{llllcc}
\hline \multicolumn{1}{c}{ Variable } & Hospital & $\mathrm{N}$ & Mean & Mean difference & $\mathrm{p}$ (2-tailed) \\
\hline Courtesy & governmental & 266 & 0.3083 & 0.2823 & 0.0001 \\
& private & 186 & 0.0261 & & \\
Understanding & governmental & 266 & 3.7905 & -0.1669 & \\
\multirow{3}{*}{ Instruction } & private & 186 & 0.9574 & & \\
& governmental & 266 & 4.3017 & 0.2916 & \\
Preparation & private & 186 & 4.0101 & & \\
& governmental & 266 & 0.4868 & -0.0672 & \\
& private & 186 & 0.5541 & & \\
\hline
\end{tabular}

Kaiser Normalization (Table 2). The results indicated that there were significant differences between the two types of practices in courtesy $(p=0.0001)$ and instruction $(p=0.000)$. There was a difference between the two types of practices in both understanding and preparation, but it was not statistically significant (Table 3).

Using ANOVA test, there was no significant difference between age groups and education for all the four factors. The t-Test showed marginal differences between males and females in all four behaviour categories, but was not significant. It also indicated a significant difference between doctors in preparation among specialist at $p=0.005$.

Satisfaction about the treatment correlated strongly, positively and directly with the two factors (courtesy and instruction). Communication satisfaction is highly and positively correlated with all four factors. Which means that as the satisfaction of communication gets high, the evaluation of these four factors is also getting high (Table 4).
Using Friedman Test, courtesy was ranked by the respondents as the most significant concern followed by understanding, instruction and preparation $(\mathrm{p}=0.0001)$ (Table 5).

Table 5. Communication factors as preferred by patients

\begin{tabular}{lc}
\hline \multicolumn{1}{c}{ Variables } & Mean Rank \\
\hline Courtesy & 2.90 \\
Understanding & 2.56 \\
Instructing & 2.86 \\
Preparation & 1.69 \\
$\mathrm{~N}$ & 440.00 \\
Chi-Square & 277.697 \\
Df & 3.00 \\
\hline
\end{tabular}

When comparing different behavioral items; factor \#4 (Made sure I was numb before working on me) was ranked as the first in rank (9.63); whereas, item \#2 (Criticized my

Table 4. Correlation between satisfaction and dentist communication

\begin{tabular}{lcccc}
\hline \multicolumn{1}{c}{ Variable } & Courtesy & Understanding & Instruction & Preparation \\
\hline $\begin{array}{l}\text { Treatment satisfaction } \\
\text { Pearson correlation }\end{array}$ & 0.152 & 0.057 & 0.207 & 0.088 \\
$\mathrm{p}(2$-tailed) & 0.002 & 0.258 & 0 & 0.076 \\
$\begin{array}{l}\text { Communication satisfaction } \\
\text { Pearson correlation }\end{array}$ & 0.248 & 0.179 & 0.310 & 0.142 \\
$\mathrm{p}(2$-tailed) & 0 & 0 & 0 & 0.004 \\
\hline
\end{tabular}


Table 6. Different behavioral factors as ranked by the patients

\begin{tabular}{rlc}
\hline No & \multicolumn{1}{c}{ Factors } & Mean rank \\
\hline 1 & Made sure I was numb before working on me & 9.63 \\
2 & Gave me moral support during the procedure & 9.60 \\
3 & Asked me during the procedure if I were having any discomfort & 9.39 \\
4 & Was patient with me & 9.34 \\
5 & Let me know that he'd do everything he could to prevent pain & 9.34 \\
6 & Was friendly to me & 9.34 \\
7 & Asked during the procedure if I were having any discomfort & 9.25 \\
8 & Showed that he took seriously what I had to say & 8.99 \\
9 & Told me what he was going to do before starting to work & 8.99 \\
10 & Showed that he paid attention to what I said & 8.93 \\
11 & Used words that were understandable in talking about my dental care & 8.73 \\
12 & Smiled & 8.69 \\
13 & Warned me when he felt the procedure might hurt & 8.11 \\
14 & Showed that he knew what I was feeling & 8.01 \\
15 & Encouraged me to ask questions about my treatment & 7.70 \\
16 & Worked quickly but didn't rush & 7.47 \\
17 & Criticized my teeth or how I've been taking care of them & 3.84 \\
& N & Chi-Square \\
& Df & 144.00 \\
& Asymp. p & 318.359 \\
\hline
\end{tabular}

teeth or how I've been taking care of them) had the least rank (Table 6).

When comparing each behavioral factor to demographic data; items that have a significant effect were as follow: assessing and judging the patient dental care (item \#2) was significant factor at $p=0.000$ among females, patients of private hospitals and those treated by general practitioners $(p=0.000)$. Similarly, factor 5 and 17 was also significant at $\mathrm{p}=0.000$ for the governmental patients. Warning the patient about pain prior to starting it and being friendly to the patient was also significant at $p=0.001$ among patients of governmental hospitals. Assessing patient feeling during the procedure (item \#15) and being patient (item \#11) were also significant for the former group of patients at $p=0.009$. Making sure of the effectiveness of anesthesia (item \#4) along with the explanation of the procedure before starting (item \#8) were significant at $p<0.05$. The latter was more frequent in general practitioners at $p=0.005$. Considering and paying attention to patient's claims, statements (item \#Q3) was significant among females and was practiced more among specialists at $p<0.05$. Specialists were also significantly better in supporting the patient morally during treatment (item \#16) at $\mathrm{p}<0.05$; and it was of significance to persons above 50 years at $p<0.05$. Similarly, encouraging the patient to ask treatment (item \#6) 
was significantly high among specialists and females at $p<0.05$. On the other hand, appreciating patient feelings (item \#5) was significantly practiced by general practitioners at $\mathrm{p}<0.05$.

\section{DISCUSSION}

The ability of the dentist to communicate is a major issue in the management of both the patients and the clinic. Most of the previous studies indicated that communication was one of the crucial traits in the ideal dentist from patients' point of view [5,18]. This research indicated that Saudi dentists practiced significantly most of the behaviours that is essential in the interaction with patients as an ideal dentist $[5,17]$. It seems that patients' main concern was the courtesy and this was a key factor to increase their satisfaction. It increased satisfaction about both the dentist interaction and treatment rendered. Similarly, evaluating dental care of the patients increased their satisfaction. This is was of special interest among young age males. In the literature, that behavioural aspect was rated as one of the first five traits in the ideal dentist $[5,17]$.

Similar to others, informativeness was one of the essential issues in both communication and satisfaction $[5,18,19]$. Information through Direct-to-Consumer Advertising can have good effects on the doctor-patient relationship when the accuracy and relevance is increased [20]. It enhances clinicians' communication and negotiation skills [20]. Dental 3D Multimedia (D3DM) System has been also reported to possess positive effects on dentist-patient communications, improving the mutual understanding between them [21].

The result of this investigation supports the interactive dentist behaviour. Interactive dentist behaviour appears to be a powerful factor to gain patients' satisfaction, rapport and positive attitude [2].

Moral support, appreciating patient's feelings, explaining the procedure and encouraging the patient to ask were all factors that were rated positively in this investigation. Previous researches comparing dentist and patient behaviour indicated that those characteristics were rated as an essential aspect of the professional competence [22]. In concordance; it increased significantly the satisfaction among our sample. Meeting patient expectation was reported to increase the satisfaction and treatment outcome $[5,19]$. Trust, personal and human aspects was identified as a major issue in the patient-doctor relationship [23].

In agreement with others, patient satisfaction was higher among females [5,17]. Patient satisfaction is reported to improve when the dentist's behaviour corresponds to what is considered as ideal dentist [17,24]. Satisfaction plays an important role in patient compliance, follow up visits, improved dental care and oral health $[3,5]$.

Dentist-patient communication is an important issue. It has its role in patients' satisfaction and treatment success. Many researches have addressed this topic in the West. To the best of our knowledge, this issue was not investigated among Saudis or any other Arabic country population.

Within the limitation of this study, it could be concluded that Saudi dentist communication was satisfactory from patient view. Courtesy was the most important factor to gain Saudi patient satisfaction. Providing information, giving moral support, appreciating patients feeling and explaining the procedure were also positively linked to patient satisfaction. Simple questions and information can greatly affect the quality of communication between the dentist and patients.

\section{REFERENCES}

1. Choi Y, Dodd V, Watson J, Tomar SL, Logan HL, Edwards H. Perspectives of African Americans and dentists concerning dentist-patient communication on oral cancer screening. Patient Edu Couns 2008;71:41-51.

2. Gale EN, Carlsson SG, Eriksson A, Jontell M. Effects of dentists' behaviour on patients' attitudes. J Am Dent Assoc 1984;109(3):444-6. 
3. Corah NL, O'Shea RM, Bissell GD. The dentist-patient relationship: perceptions by patients of dentist behaviour in relation to satisfaction and anxiety. J Am Dent Assoc 1985;111(3): 443-6.

4. Corah NL, O'Shea RM, Bissell GD, Thines TJ, Mendola P. The dentist-patient relationship: perceived dentist behaviours that reduce patient anxiety and increase satisfaction. J Am Dent Assoc 1988;116(1):73-6.

5. Lahti S, Tuutti H, Hausen H, Kaarlanen R. Patients' expectations of an ideal dentist and their views concerning the dentist they visited: do the views conform to the expectations and what determines how well they conform? Commun Dent Oral Epidemiol 1996;24(4):240-4.

6. William S, Weinman J, Dale J. Doctor-patient communication and patient satisfaction: a review. Family Practice 1998;15:480-92.

7. Kurtz SM. Doctor-Patient Communication: Principles and Practices. Can J Neurol Sci 2002;29 Suppl. 2: S23-9.

8. Koerber A, Gajendra S, Fulford RL, BeGole E, Evans CA. An Exploratory Study of Orthodontic Resident Communication by Patient Race and Ethnicity. J Dent Edu 2004;68(5):553-62.

9. Bartlett G, Blais R, Robyn Tamblyn R, Richard J. Clermont RJ, Mac Gibbon B. Impact of patient communication problems on the risk of preventable adverse events in acute care settings. CMAJ 2008;178(12):1555-62.

10. Lukoschek P, Fazzari M, Marantz P. Patient and physician factors predict patients' comprehension of health information. Patient Edu Couns 2003;50:201-10.

11. Graugaard PK, Finset A. Trait Anxiety and Reactions to Patient-Centered and Doctor-Centered Styles of Communication: An Experimental Study. Psychosom Med 2000;62(1):33-9.

12. Street R. Information giving in medical consultations: the influence of patients communicative styles and personal characteristics. Soc Sci Med 1991;32(5):541-8.

13. Waitzkin H. Information giving in medical care. J Health Soc Behav 1985;26:81-101.

14. Willems S, De Maesschalck S, Deveugele M, Derese A, De Maeseneer J. Socio-economic status of the patient and doctor-patient communication: does it make a difference? Patient Edu Couns 2005;56:139-46.

15. Parker MA. A perspective on doctor-patient communication in the dental office. NC Med J 2007;68(5):365-7.

16. Lahti S, Tuutti H, Hausen H, Kaariainen R. Dentist and patient opinions about the ideal dentist and patient: developing a compact questionnaire. Commun Dent Oral Epidemiol 1992;20(4):229-34.

17. Lahti S, Tuutti H, Hausen H, Kaariainen R. Comparison of ideal and actual behavior of patients and dentists during dental treatment. Commun Dent Oral Epidemiol 1995;23(6):374-8.

18. Lahti S, Tuutti H, Hausen H, Kaariainen R. Opinions of different subgroups of dentists and patients about the ideal dentist and the ideal patient. Commun Dent Oral Epidemiol 1995;23(2):89-94.

19. Sondell K, Soderfeldt B, Palmqvist S. Dentist-patient communication and patient satisfaction in prosthetic dentistry. Int J Prosthodont 2002;15(1):28-37.

20. Murray E, Lo B, Pollack L, Donelan K, and Lee K. Directto-Consumer Advertising: Physicians' Views of Its Effects on Quality of Care and the Doctor-Patient Relationship. J Am Board Fam Pract 2003;16:513-24.

21. Hu J, Yu H, Shao J, Li Z, Wang J, Wang Y. An evaluation of the Dental 3D Multimedia System on dentist-patient interactions: A report from China. Int J Med Inform 2008;77(10): 670-8.

22. Lahti S, Verkasalo M, Hausen H, Tuutti H. Ideal role behaviours as seen by dentists and patients themselves and by their role partners: do they differ? Commun Dent Oral Epidemiol 1996;24(4):245-8.

23. Lings P, Evans P, Seamark D, Seamark C, Sweeney K, Dixon $\mathrm{M}$, et al. The doctor-patient relationship in US primary care. J R Soc Med 2003;96:180-4.

24. Schouten BC, Eijkman MA, Hoogstraten J. Dentists' and patients' communicative behaviour and their satisfaction with the dental encounter. Commun Dent Health 2003; 20(1):11-5.

This work is available in Open Access model and licensed under a Creative Commons Attribution-NonCommercial 3.0 Poland License - http://creativecommons.org/ licenses/by-nc/3.0/pl/deed.en. 